\title{
Market Segmentation, Price Disparity, and Transmission of Pricing Information: Evidence from Class A and $H$ Shares of Chinese Dual-Listed Companies*
}

\author{
Kyung-Won Kim", Yong Hyeon Kim², Chul W. Park³ , Hong-Ghi Min"\# \\ ${ }^{1}$ Department of International Commerce, Kyonggi University, Suwon, Republic of Korea \\ ${ }^{2}$ Department of Finance and Banking, Hanyang Cyber University, Seoul, Republic of Korea \\ ${ }^{3}$ School of Business, The University of Hong Kong, Hong Kong \\ ${ }^{4}$ Department of Management Science, KAIST, Daejeon, Republic of Korea \\ Email: "wkim@kyonggi.ac.kr, yhkim@hycu.ac.kr, acparkc@hku.hk, " $\underline{\text { hmin@@kaist.ac.kr }}$
}

Received 22 June 2015; accepted 6 September 2015; published 9 September 2015

Copyright (C) 2015 by authors and Scientific Research Publishing Inc.

This work is licensed under the Creative Commons Attribution International License (CC BY). http://creativecommons.org/licenses/by/4.0/

(c) (i) Open Access

\begin{abstract}
This paper examines the transmission of pricing information and the volatility of dual-listed stocks between class $A$ and $H$ shares of Chinese companies. First, using firm level data, we show that there is a large price discount for $H$ shares relative to the A shares. Second, when we divide the firms into a high price disparity group and a low price disparity group, we find that the high price disparity group's pricing information transmission is stronger than the low price disparity group during the pre-liberalization period (in terms of significant mean coefficients). Third, when we divide the entire sample period into a pre-liberalization period and a post-liberalization, we find that the mean value spillover is stronger during the post-liberalization period for the low price disparity group. Finally, we report that during the post-liberalization period, the volatility spillover increases from $A$ shares to $H$ shares while it decreases from $H$ shares to $A$ shares. This implies that there is an information advantage of $\mathrm{H}$ shares, disappearing with the liberalization of A shares.
\end{abstract}

\section{Keywords}

Market Segmentation, Price Disparity, Transmission of Pricing Information, A and H Shares, GJR-GARCH (1,1)-M Model

\footnotetext{
*This work was supported by the National Research Foundation of Korea Grant funded by the Korean Government (NRF-2011-013-B00044).

\#Corresponding authors.

How to cite this paper: Kim, K.-W., Kim, Y. H., Park, C. W., \& Min, H.-G. (2015). Market Segmentation, Price Disparity, and Transmission of Pricing Information: Evidence from Class A and $\mathrm{H}$ Shares of Chinese Dual-Listed Companies. Journal of Financial Risk Management, 4, 124-142. http://dx.doi.org/10.4236/jfrm.2015.43011
} 


\section{Introduction}

In many emerging countries, stock markets are segmented to allow companies to issue shares that attract foreign funds while minimizing the risk of market destabilization and loss of ownership control to foreign investors. Under these segmented markets, two classes of shares are normally issued: 1) restricted shares that can only be traded by local investors and 2) unrestricted shares that can be traded by both local and overseas investors. Although restricted and unrestricted shareholders receive identical voting rights and cash flows, it has been reported that unrestricted shares usually trade at a premium over restricted shares. A notable exception to this trend has been occurring in China. Specifically, unlike other countries, China's stock market provides substantial and persistent price discounts instead of a premium on B shares (the equivalent to unrestricted shares in other markets) relative to A shares (the equivalent to restricted shares).

In China, the Shanghai Stock Exchange (SHSE) was established in December 1990, after which the Shenzhen Stock Exchange (SZSE) opened in July 1991. The two exchanges are not allowed to have cross-listings. Some firms issue two types of shares in China: class A shares which are quoted in Renminbi (RMB) and traded among Chinese citizens, and class B shares which are quoted in foreign currencies (U.S. dollars on the SHSE and Hong Kong dollars on the SZSE) and traded among non-Chinese citizens or overseas Chinese. The A and B shares are listed on the SHSE and SZSE in China. Similar to the firms issuing both A shares and B shares, some companies issue both A shares and $\mathrm{H}$ shares, which are listed in the Hong Kong Stock Exchange (HKSE). Chinese citizens are forbidden from trading $\mathrm{H}$ shares. In fact, Hong Kong has an $\mathrm{H}$ share market and a "red-chip” market. Red-chip stocks are stocks from Chinese firms incorporated outside China and listed in Hong Kong. The actual businesses are based on China and controlled by the central, provincial, or municipal governments of China. Therefore, foreign investors can trade in the B share market, H share market, and red-chip market. Unlike A and B shares, A and $\mathrm{H}$ shares are segmented in terms of their listing and trading locations. For example, while A shares are traded by local investors in the SHSE and SZSE, H shares are traded only by investors in Hong Kong.

The unique nature of segmentation between $\mathrm{A}$ shares and $\mathrm{H}$ shares indicates that the price discounts of $\mathrm{H}$ shares over A shares may be caused by local market risks and investors' attitudes. There have been two important stock market liberalizations in China. The first was the opening of the B share market to local Chinese investors in February 2001. The B share market responded to this opening with great fanfare. The SHSE and SZSE's B share indices rose by $178 \%$ and 122\%, respectively, from February 2001 to June 2001, whereas the A share indices increased by only $11 \%$ and $9 \%$, respectively, in the same period. The second was the approval of a scheme to allow Qualified Foreign Institutional Investors (QFII) into the A share market in December 2002. In contrast to the first reform, it seems that the QFII scheme did not have an obvious impact on the A share market. Before the opening of the $\mathrm{B}$ share market to local Chinese investors, the $\mathrm{B}$ share and $\mathrm{H}$ share price discounts remained at a similar level. However, after the opening of the market, the B share price discount reduced dramatically, whereas the $\mathrm{H}$ share price discount remained unchanged. The liberalization reforms were completed in December 2002.

We believe that the liberalization reforms impacted the price disparity and transmission of pricing information between the Chinese market and Hong Kong market. This paper examines the impact of liberalization on these stock markets. To do this, our overall sample was divided into two sub-periods: the period before December 2002 and the period after December 2002. When stock is traded at different prices, it will lead to arbitrage pressure $^{1}$. It is very likely that if the price disparity between two shares becomes larger, the effect of the price disparity on the transmission of pricing information between two shares will become stronger due to an increased arbitrage opportunity pressure. Most of the previous studies have examined the transmission of pricing information at the level of the stock market index. However, empirical tests were performed at a firm-specific level in this study. The sample included companies that issued both A and H shares.

Most time series of financial data have problems related to a fat tail and heteroscedasticity. The Autoregressive Conditional Heteroscedasticity (ARCH) model introduced by Engle (1982) and the Generalized Autoregressive Conditional Heteroscedasticity (GARCH) model developed by Bollerslev (1986) are believed to be suitable to analyze time series data in order to handle these problems. More recently, the GARCH model developed by Glosten, Jaganathan, \& Runkle (1993) (hereafter GJR) became widely known as appropriate to analyze

\footnotetext{
${ }^{1}$ Arbitrage trading between A-shares and H-shares is difficult due to currency exchange restrictions and stock regulations. However, W. Peng, H. Miao, and N. Chow (2007) suggested that the price differentials of A and H share prices are stationary, and A and H share prices have a trend of convergence. There could be evidence supporting the existence of investment activities for which arbitrage on the price gaps probably goes through informal channels.
} 
not only the symmetric spillover effect, but also the asymmetric spillover effect.

Our work extends the existing studies in the following ways. First, our paper is the first to directly examine the transmission effect by comparing firms with a low price discount with those with a high price discount. Second, this study compared the different transmission of pricing information during the pre-liberalization period and the post-liberalization period between A share and $\mathrm{H}$ share markets. Third, the current study employed the GJR-GARCH model to examine the spillover effect more precisely.

The rest of this paper is organized as follows. The finance literature related to the current topic is reviewed in Section 2, after which the data and methodology are discussed in Section 3. Section 4 reports and discusses the empirical results. Finally, the conclusions are presented in Section 5.

\section{Literature Review on the Discount Puzzles in the Chinese Stock Market}

Previous finance studies reported that stocks of the foreign-only class have higher prices than those of the domestic-only class. Hietala (1989) found a substantial premium for the foreign-only share price relative to the domestic-only share price in the Finnish stock market for 1984-85. Bailey \& Jagtiani (1994) reported an average premium of 19 percent on the Alien Board of the Thailand Stock Exchange. Stulz and Wasserfallen (1995) also documented foreign investors paying higher prices than domestic investors in Switzerland. Domowitz, Glen, and Madhavan (1997) found significant stock price premiums for B share stocks in the Mexican market. An exception to this trend is China. In his pioneering work, Bailey (1994) examined eight Chinese B share stocks for the period from March 1992 to March 1993 and reported a significant discount in the B share prices relative to their A share counterparts. This puzzling phenomenon was confirmed by the studies of Ma (1996); Chen, Lee, \& Rui (2001); Lee, Rui, \& Wu (2008). Over the years, academics have made efforts to explain this puzzling phenomenon.

So far, there are four potential explanations about the source of price differences between A and B shares: the differential demand hypothesis (Stulz and Wasserfallen (1995); Domowitz, Glen, and Madhavan (1997)), the asymmetric information hypothesis (Chakravarty, Sarkar, \& Wu, 1998), the liquidity hypothesis (Amihud and Mendelson (1986)), and the differential risk hypothesis (Ma, 1996). Kim \& Choi (2009) noticed that most B shares are traded by small retail investors, whereas most $\mathrm{H}$ shares are traded by foreign institutional investors. They found momentum to be the most important factor to explain the price discount for $\mathrm{H}$ shares relative to A shares, as institutional investors frequently use the momentum investment strategy. Wei \& Zeng, (2011) examined the causality between the liquidity and price disparity of $\mathrm{H}$ and $\mathrm{N}$ shares. They reported that the causality between price disparity and liquidity runs both ways. Wei \& Zeng (2011) also showed that H shares have a higher liquidity and lower short-term returns. Cai, McGuinness, \& Zhang (2012) examined the co-integration relationship between the $\mathrm{H}$ and A share prices of dual-listed Chinese stocks. They found that the changes in policy and corporate governance seemed to be the crucial force in increasing the efficiency of reducing price disparity and correcting errors. They also showed that weakening informational asymmetries may have contributed to much of the changes observed in the markets' relative pricing.

The studies above tried to investigate the puzzling phenomenon and find the determinants of the discount puzzles. At the same time, other papers tried to find the transmission and spillover effect of the stock market indices or Chinese companies that are cross-listed in the Shanghai, Hong Kong, and U.S. markets. Zhang \& Zhao (2003) argued that Chinese companies could issue A, B, and H shares to Chinese, foreign, and Hong Kong investors, respectively. They found that the price differential among the shares was caused by the country-specific risks related to the Chinese stock market among the three groups of investors. Li, Yi, \& Su (2011) also investigated the spillover effect of the returns of cross-listed Chinese stocks that are traded simultaneously in the Shanghai, Hong Kong, and U.S. markets. They reported a strong, unidirectional spillover effect from the U.S. market to the Shanghai market. They also found a significant two-way influence existing between the Hong Kong and U.S. markets. Chong \& Su (2006) investigated the co-movement between the A and H shares of cross-listed Chinese firms. They found that only a small portion of the cross-listed Chinese firms experienced co-movement in their A and $\mathrm{H}$ share prices. Their findings suggest segmentation of China's and Hong Kong stock markets.

Wang \& Iorio (2007) examined the agenda of market segmentation and integration regarding China's stock markets. Specifically, they analyzed the agenda of China-related share markets in both the Hong Kong and world markets. They found the A share market to be segmented during the sample period. However, during the 
sub-period, they observed a higher level of integration between the A and B share markets, as well as the A and $\mathrm{H}$ share markets. They argued that integration between the A and B share markets was attributable to the opening of the B share market in February 2001, and that the integration between the A and H share markets was due to the increasing economic integration of Hong Kong and China.

Xu \& Fung (2002) analyzed the patterns of information flow for China-backed stocks that were dual-listed in Hong Kong and New York using a bivariate GARCH model. They found the cross-listed stocks to have significant mutual feedback of information between the Hong Kong and New York markets in terms of pricing and volatility. They also found that the stocks listed in Hong Kong played a bigger role in transmitting information during the pricing process, while stocks listed in New York played a more significant role in the volatility spillover. Kutan \& Zhou (2006) analyzed the determinants of returns and the volatility of nine Chinese ADRs as listed on the New York Stock Exchange by using an ARCH model. They reported that the Hong Kong market (underlying market), U.S. market (host market), and local markets (Shanghai A and B) were all important determinants of the returns of Chinese ADRs. Among the three markets, the Hong Kong market was observed to have the most significant effect on the mean returns of the ADRs. However, the only shocks to the underlying markets were significant in terms of the determinants of conditional volatility. Lee, Rui, \& Wu (2008) found that after the opening of the B share market in February 2001, the B share price discount declined considerably, while the $\mathrm{H}$ share price discount remained virtually unchanged.

Most ADR markets and underlying markets have different opening and closing hours. However, the transmission of information can be detected more clearly if the trading hours of both markets are somewhat concurrent. This concurrency was examined while determining the transmission of information between the Hong Kong and Chinese markets. Kim (2011) investigated the transmission of pricing information of the stock market indices between the Chinese and Hong Kong stock markets, and found no causal relations to be present between the two classes of stocks. He did not, however, analyze the transmission at a company-specific level. Wei \& Zeng (2011) also showed the Hong Kong market to be more active in responding to arbitrage opportunities. Even though arbitrage trading between $\mathrm{A}$ shares and $\mathrm{H}$ shares is difficult due to both the currency exchange restrictions and stock regulations, Peng, Miao, \& Chow (2007) suggested A and H share prices tend to move towards convergence. There could be investment activities in which arbitrage on the price gaps goes through informal channels. Price disparity or arbitrage pressure may impact the transmission of pricing information between both markets.

\section{Data and Methodology}

\subsection{Data}

We first retrieved the daily stock returns of $\mathrm{A}$ and $\mathrm{H}$ shares from the Primark Datastream database that covers the period from July $3^{\text {rd }}, 1997$ through June $1^{\text {st }}$, 2009. There were 53 companies in total which issued both A shares in the SHSE or SZSE and H shares in the HKSE. Of these, twelve firms had data available since the beginning of the sample period. Finally, the sample size was reduced to eight firms. The final sample of eight companies consisted of those dual-listed in both the Chinese A share market and Hong Kong H share market from the entire period of July $3^{\text {rd }}, 1997$ to June $1^{\text {st }}$, 2009. Table 1 shows the company name, ticker, and number of the total A and $\mathrm{H}$ shares of each sample, respectively.

The current study divided the eight companies into two sub-groups: those with a high price discount or disparity, and those with a low price discount or disparity with respect to the median value. The former group was composed of four companies that had a price discount or disparity of more than $80 \%$, while the latter group was made up of four firms that had a price discount or disparity of less than $50 \%$ during the sample period.

The stocks with a high price discount or disparity are presented in Table 2 in order from highest to lowest. Similarly, Table 3 shows the stocks with a low price discount or disparity in order from lowest to highest.

Since the A shares were quoted in RMB and the $\mathrm{H}$ shares were quoted in Hong Kong dollars, the $\mathrm{H}$ shares were converted into the denomination of RMB. Specifically, the daily Hong Kong dollars were adjusted to RMB by using the daily exchange rate. Thus, all data were expressed in terms of RMB for comparison. In this study, the price differences, along with the pricing and volatility transmission of the dual-listed stocks, were analyzed using daily data from both markets. This was done not only for the entire sample period, but also for the subperiods before and after the December 2002 Chinese liberalization. 
Table 1. Dual-Listed stocks.

\begin{tabular}{cccc}
\hline Company Name & Ticker & Number of A shares & Number of H shares \\
\hline BEIREN PRINT.MCH. & BPM & 322,000 & 100,000 \\
DONGFENG ELT.TECH. & DME & 313,560 & 170,000 \\
GUANGZHOU SHPYD.INTL. & GUA & 337,280 & 157,398 \\
LUOYANG GLASS & LGC & 250,018 & 250,000 \\
MAANSHAN IRON \& STL & MIS & $5,025,620$ & $1,732,929$ \\
NANJING PANDA ELEC. & NNP & 413,015 & 242,000 \\
NORTHEAST ELECT.DEV. & NET & 615,420 & 257,950 \\
TSINGTAO BREWERY & TTB & 653,150 & 655,069 \\
\hline
\end{tabular}

Table 2. Dual-Listed stocks with high price discount or disparity in order.

\begin{tabular}{ccc}
\hline Company Name & Number of A shares & Number of H shares \\
\hline LUOYANG GLASS & 250,018 & 250,000 \\
NORTHEAST ELECT.DEV. & 615,420 & 257,950 \\
NANJING PANDA ELEC. & 413,015 & 242,000 \\
BEIREN PRINT.MCH. & 322,000 & 100,000 \\
\hline
\end{tabular}

Table 3. Dual-Listed stocks with low price discount or disparity in order.

\begin{tabular}{ccc}
\hline Company Name & Number of A shares & Number of H shares \\
\hline DONGFENG ELT.TECH. & 313,560 & 170,000 \\
TSINGTAO BREWERY & 653,150 & 655,069 \\
GUANGZHOU SHPYD.INTL. & 337,280 & 157,398 \\
MAANSHAN IRON \& STL & $5,025,620$ & $1,732,929$ \\
\hline
\end{tabular}

\subsection{Methodology}

The spillover effect between the international stock markets can be broken down into price spillover and volatility spillover effects. The summary statistics demonstrated that the time series data did not follow a normal distribution. Hence, the heteroscedasticity model should be employed to capture the transmission of information between the Chinese A share market and the Hong Kong H share market.

The heteroscedasticity model was introduced by Engle (1982) and developed by Bollerslev (1986). The GJR-GARCH model (Glosten, Jaganathan, \& Runkle, 1993) was also found to be a good fit for capturing both the symmetric information spillover effect, as well as the asymmetric information spillover effect.

Based on the research from Engle (1982) and Bollerslev (1986), we included some exogenous variables to investigate the attributes of the data. We also utilized a GJR-GARCH(1,1)-M model to examine the transmission of information between the Chinese and Hong Kong markets. The model allowed us to investigate both the pricing transmission and the volatility spillover of the stocks dual-listed on the Chinese and Hong Kong markets.

The mean and variance equations for the GJR-GARCH(1,1)-M model were specified as follows:

Equation (1) shows the conditional mean for Hong Kong $H$ shares:

$$
H K_{t}=a_{1,0}+a_{1,1} C A_{1, t}+a_{1,2} h_{1, t}+\varepsilon_{1, t}
$$

Equation (2) shows the conditional variance for Hong Kong $\mathrm{H}$ shares:

$$
h_{1, t}=\omega_{1,0}+\beta_{1,1} h_{1, t-1}+\gamma_{1,2} e_{t-1}^{2}+\delta_{1,3} C A A_{1, t-1}+\theta_{1,4} \varepsilon_{t-1}^{2} I_{1, t-1}
$$

Equation (3) shows the conditional mean for Chinese A shares:

$$
C A_{1, t}=a_{1,0}+a_{1,1} H K_{1, t}+a_{1,2} h_{1, t}+e_{1, t}
$$

Equation (4) shows the conditional variance:

$$
h_{1, t}=\omega_{1,0}+\beta_{1,1} h_{t-1}+\gamma_{1,2} e_{t-1}^{2}+\delta_{1,3} H K K_{1, t-1}+\theta_{1,4} e_{t-1}^{2} I_{1, t-1}
$$


In the equations, $\boldsymbol{C A}$ and $\boldsymbol{H} \boldsymbol{K}$ reflect the stock returns of the Chinese A shares and Hong Kong $\mathrm{H}$ shares, re-

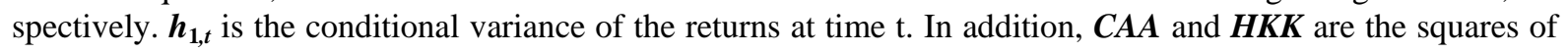
standard errors for the Chinese A shares and Hong Kong $\mathrm{H}$ shares, respectively. $\varepsilon_{t-1}$ in equation (2) is the residual of Chinese A shares, while $e_{t-1}$ in Equation (4) is the residual of Hong Kong H shares. $I_{1, t-1}$ is a dummy variable represented by 0 or 1 , which equals 1 if the residual is negative, and 0 otherwise.

\section{Empirical Results}

The transmission of return and volatility of stocks dual-listed in the Chinese and Hong Kong markets were investigated. To allow for the impact of Chinese liberalization on the stock markets, the spillover effect was analyzed not only for the entire sample period, but also for two other sub-periods: the period before December 2002 and the period after December 2002.

\subsection{Analysis for the Whole Sample Period Analysis}

The results of the spillover effects in returns and volatilities from the Chinese A shares to Hong Kong $\mathrm{H}$ shares are shown in Table 4(a) for firms with low price discounts during the entire sample period. In the table, the

Table 4. (a) (b) Spillover effects in returns and volatilities from Chinese A shares to Hong Kong H shares during the whole sample period.

(a)

\begin{tabular}{|c|c|c|c|c|c|}
\hline & & \multicolumn{2}{|c|}{ DME } & \multicolumn{2}{|c|}{ ТТВ } \\
\hline & & Coefficient & z-Statistic & Coefficient & z-Statistic \\
\hline & $a_{0}$ & 0.002209 & 0.273601 & 0.007669 & 1.023971 \\
\hline & $a_{1}$ & 0.17704 & 5.153214 & 0.12293 & 7.911278 \\
\hline & $a_{2}$ & 0.047138 & 0.332308 & 0.01277 & 0.166328 \\
\hline & $\omega$ & 3.325247 & 2.847543 & 1.50436 & 5.323386 \\
\hline & $\beta$ & 0.190294 & 3.070732 & 0.244286 & 4.697564 \\
\hline & $\gamma$ & 0.629555 & 6.828258 & 0.605791 & 13.12283 \\
\hline & $\delta$ & 0.003664 & 0.168466 & 0.072397 & 2.157113 \\
\hline & $\theta$ & 0.024952 & 0.751015 & 0.080555 & 1.197004 \\
\hline \multirow[t]{13}{*}{ LR(5) for } & $H_{2}: a_{1}=\beta=\gamma=\delta=\theta=0$ & \multicolumn{2}{|c|}{62.4877} & \multicolumn{2}{|c|}{186.41} \\
\hline & Log-likelihood & \multicolumn{2}{|c|}{-8743.627} & \multicolumn{2}{|c|}{-8000.279} \\
\hline & Number of obs. & \multicolumn{2}{|c|}{3107} & \multicolumn{2}{|c|}{3107} \\
\hline & & \multicolumn{2}{|c|}{ GUA } & \multicolumn{2}{|c|}{ MIS } \\
\hline & & Coefficient & z-Statistic & Coefficient & z-Statistic \\
\hline & $a_{0}$ & 0.019516 & 3.058173 & 0.00348 & 0.835627 \\
\hline & $a_{1}$ & 0.287551 & 12.65655 & 0.290484 & 10.65928 \\
\hline & $a_{2}$ & -0.27486 & -2.511124 & 0.032294 & 1.508261 \\
\hline & $\omega$ & 1.3032 & 4.411056 & 0.422331 & 3.358629 \\
\hline & $\beta$ & 0.183199 & 6.704147 & 0.142621 & 6.086859 \\
\hline & $\gamma$ & 0.750318 & 23.15667 & 0.823444 & 31.87033 \\
\hline & $\delta$ & 0.042307 & 2.229784 & 0.034111 & 2.501968 \\
\hline & $\theta$ & -0.039503 & -2.022096 & -0.003807 & -71764.5 \\
\hline \multirow[t]{3}{*}{ LR(5) for } & $H_{2}: a_{1}=\beta=\gamma=\delta=\theta=0$ & \multicolumn{2}{|c|}{592.5303} & \multicolumn{2}{|c|}{$2.09 \mathrm{E}+09$} \\
\hline & Log-likelihood & \multicolumn{2}{|c|}{-8720.775} & \multicolumn{2}{|c|}{-8366.335} \\
\hline & Number of obs. & \multicolumn{2}{|c|}{3107} & \multicolumn{2}{|c|}{3107} \\
\hline
\end{tabular}

The mean and variance Spillover GJR-GARCH(1,1)-M model: $\quad H K_{t}=a_{1,0}+a_{1,1} C A_{1, t}+a_{1,2} h_{1, t}+\varepsilon_{1, t} \quad h_{1, t}=\omega_{1,0}+\beta_{1,1} h_{t-1}+\gamma_{1,2} e_{t-1}^{2}+\delta_{1,3} H K K_{1, t-1}+\theta_{1,4} e_{t-1}^{2} I_{1, t-1}$ Where CA and HK stand for stock returns of the Chinese A shares and Hong Kong $\mathrm{H}$ shares, respectively. CAA and HKK indicate squares of the standard errors of Chinese A shares and Hong Kong H shares, respectively. $e_{t-1}$ is the residual. $I_{1, t-1}$ is a dummy variable. Panel A: Whole sample period (1993.07.15-2009.06.01): Firms with low price discount. 
(b)

\begin{tabular}{|c|c|c|c|c|}
\hline & \multicolumn{2}{|c|}{ LGC } & \multicolumn{2}{|c|}{ NET } \\
\hline & Coefficient & z-Statistic & Coefficient & z-Statistic \\
\hline$a_{0}$ & -0.005388 & -0.832802 & 0.001772 & 0.575514 \\
\hline$a_{1}$ & 0.137613 & 8.668421 & 0.366219 & 8.109146 \\
\hline$a_{2}$ & 0.235863 & 2.303057 & -0.128872 & -2.800504 \\
\hline$\omega$ & 0.707442 & 5.786206 & -0.008068 & -1.177496 \\
\hline$\beta$ & 0.158348 & 6.907695 & 0.19709 & 7.084551 \\
\hline$\gamma$ & 0.838396 & 40.19217 & 0.707099 & 17.3629 \\
\hline$\delta$ & 0.008039 & 2.22465 & 0.540969 & 2.556975 \\
\hline$\theta$ & -0.015372 & -23.58967 & 0.074694 & 3.631461 \\
\hline $\begin{array}{c}\text { LR(5) for } \\
H_{2}: a_{1}=\beta=\gamma=\delta=\theta=0\end{array}$ & \multicolumn{2}{|c|}{4456.305} & \multicolumn{2}{|c|}{1213.184} \\
\hline Log-likelihood & \multicolumn{2}{|c|}{-7956.845} & \multicolumn{2}{|c|}{-8913.181} \\
\hline \multirow[t]{3}{*}{ Number of obs. } & \multicolumn{2}{|c|}{3107} & \multicolumn{2}{|c|}{3107} \\
\hline & \multicolumn{2}{|c|}{ NNP } & \multicolumn{2}{|c|}{ BPM } \\
\hline & Coefficient & z-Statistic & Coefficient & z-Statistic \\
\hline$a_{0}$ & 0.00914 & 1.250745 & 0.000464 & 0.058573 \\
\hline$a_{1}$ & 0.299229 & 10.60139 & 0.217437 & 8.27211 \\
\hline$a_{2}$ & -0.162668 & -1.066155 & -0.013549 & -0.133207 \\
\hline$\omega$ & 1.753336 & 2.171233 & 2.015278 & 4.110949 \\
\hline$\beta$ & 0.132669 & 4.625835 & 0.203347 & 5.281107 \\
\hline$\gamma$ & 0.785127 & 16.72463 & 0.594885 & 9.646272 \\
\hline$\delta$ & -0.020478 & -0.641786 & 0.119138 & 2.644042 \\
\hline$\theta$ & 0.079819 & 1.06088 & -0.004699 & -6.744777 \\
\hline $\begin{array}{c}\text { LR(5) for } \\
H_{2}: a_{1}=\beta=\gamma=\delta=\theta=0\end{array}$ & \multicolumn{2}{|c|}{239.6017} & \multicolumn{2}{|c|}{255.6381} \\
\hline Log-likelihood & \multicolumn{2}{|c|}{-8969.65} & \multicolumn{2}{|c|}{-8262.142} \\
\hline Number of obs. & \multicolumn{2}{|c|}{3107} & \multicolumn{2}{|c|}{3107} \\
\hline
\end{tabular}

Panel B: Whole sample period (1993.07.15-2009.06.01): Firms with high price discount

coefficients of $a_{1}$ that indicate the spillover effect of price disparity between the markets were all significant at the $1 \%$ critical level. These results reflect the transmission of pricing information. The coefficients of $\delta$ indicate that the spillover effect of volatility between the markets was significant for 3 out of the 4 firms. The result implies that for most of the stocks, transmission of volatility information occurred. The coefficients of $\theta$ that indicated the leverage effects were significant for 2 out of 4 firms.

The results of the spillover effects in returns and volatilities from Chinese A shares to Hong Kong $\mathrm{H}$ shares for firms with high price discounts during the entire sample period can be seen in Table 4(b).

Similar to Table 4(a), the coefficients of $a_{1}$ that indicate the spillover effect of price disparity were all significant at the $1 \%$ level. Likewise, the coefficients of $\delta$ were significant for 3 out of the 4 firms. Again, these results suggest a spillover effect for the pricing and volatility information occurred. However, unlike Table 4(a), the coefficients of $\theta$ indicate the leverage effect was significant for 3 out of 4 companies, implying transmission of leverage information. 
The results of the spillover effects in returns and volatilities from Hong Kong $\mathrm{H}$ shares to Chinese A shares for firms with low price discounts during the entire sample period are shown in Table 5(a).

In the table, the coefficients of $a_{1}$ that indicate the spillover effect of price disparity were all significant at the $1 \%$ level. The coefficients of $\delta$ indicating the spillover effect of volatility were significant for 2 out of 4 firms. In addition, the coefficients of $\theta$ indicating a leverage effect were significant for 3 out of 4 firms.

Table 5(b) documents the results of the spillover effects in returns and volatilities from Hong Kong $\mathrm{H}$ shares to Chinese A shares for firms with high price discounts during the sample period. Similar to Table 5(a), the coefficients of $a_{1}$ indicating the spillover effect of price disparity was all significant at the $1 \%$ level. The coefficients of $\delta$ were also significant for 2 out of 4 firms. Again, similar to Table 5(a), the coefficients of $\theta$ indicating the leverage effect were significant for 3 out of 4 companies, implying that a spillover effect of leverage information occurred.

The results from Table 4(a) to Table 5(b) showed that all the coefficients of $a_{1}, a_{2}, \beta, \gamma, \delta$, and $\theta$ were not zero. The log-likelihood statistics was rejected at the $1 \%$ significance level, indicating that the model appeared to be well-specified and appropriate. Overall, the results of panel A and panel B were essentially iden-

Table 5. (a) (b) Spillover effects in returns and volatilities from Hong Kong H shares to Chinese A shares during the whole sample period.

(a)

\begin{tabular}{|c|c|c|c|c|}
\hline & \multicolumn{2}{|c|}{ DME } & \multicolumn{2}{|c|}{ ТTВ } \\
\hline & Coefficient & z-Statistic & Coefficient & z-Statistic \\
\hline$a_{0}$ & 0.005746 & 0.696189 & 0.000486 & 0.044073 \\
\hline$a_{1}$ & 0.01556 & 3.798381 & 0.109969 & 8.108422 \\
\hline$a_{2}$ & -0.007377 & -0.154307 & 0.025962 & 0.597113 \\
\hline$\omega$ & 0.138171 & 17.86451 & 0.163118 & 2.880968 \\
\hline$\beta$ & 0.10956 & 20.16165 & 0.12485 & 6.084772 \\
\hline$\gamma$ & 0.884875 & 213.2433 & 0.807823 & 22.24197 \\
\hline$\delta$ & -0.001811 & -23.19578 & 0.019026 & 1.456127 \\
\hline$\theta$ & 0.000759 & 8.751957 & 0.001759 & 0.146436 \\
\hline $\begin{array}{c}\text { LR(5) for } \\
H_{2}: a_{1}=\beta=\gamma=\delta=\theta=0\end{array}$ & \multicolumn{2}{|c|}{71113.66} & \multicolumn{2}{|c|}{1163.245} \\
\hline Log-likelihood & \multicolumn{2}{|c|}{-7067.977} & \multicolumn{2}{|c|}{-6729.091} \\
\hline \multirow[t]{3}{*}{ Number of obs. } & \multicolumn{2}{|c|}{3107} & \multicolumn{2}{|c|}{3107} \\
\hline & \multicolumn{2}{|c|}{ GUA } & \multicolumn{2}{|c|}{ MIS } \\
\hline & Coefficient & z-Statistic & Coefficient & z-Statistic \\
\hline$a_{0}$ & 0.01178 & 1.323977 & 0.014846 & 0.753984 \\
\hline$a_{1}$ & 0.141166 & 12.52341 & 0.119311 & 10.50363 \\
\hline$a_{2}$ & -0.074017 & -1.073017 & -0.15153 & -1.078033 \\
\hline$\omega$ & 0.77917 & 4.154782 & 2.417259 & 2.377939 \\
\hline$\beta$ & 0.167976 & 8.237393 & 0.148771 & 4.738651 \\
\hline$\gamma$ & 0.725635 & 20.194 & 0.535059 & 4.820589 \\
\hline$\delta$ & 0.019412 & 4.326197 & 0.005097 & 1.032486 \\
\hline$\theta$ & -0.010811 & -17.02746 & -0.005039 & -9.623602 \\
\hline $\begin{array}{l}\text { LR(5) for } \\
H_{2}: a_{1}=\beta=\gamma=\delta=\theta=0\end{array}$ & \multicolumn{2}{|c|}{770.6892} & \multicolumn{2}{|c|}{95.39213} \\
\hline Log-likelihood & \multicolumn{2}{|c|}{-7601.155} & \multicolumn{2}{|c|}{-7225.701} \\
\hline Number of obs. & \multicolumn{2}{|c|}{3107} & \multicolumn{2}{|c|}{3107} \\
\hline
\end{tabular}

Panel A: Whole sample period (1993.07.15-2009.06.01): Firms with low price discount. 
(b)

\begin{tabular}{|c|c|c|c|c|}
\hline & \multicolumn{2}{|c|}{ LGC } & \multicolumn{2}{|c|}{ NET } \\
\hline & Coefficient & z-Statistic & Coefficient & z-Statistic \\
\hline$a_{0}$ & -0.008412 & -0.072549 & -0.053588 & -1.699325 \\
\hline$a_{1}$ & 0.108391 & 8.691403 & 0.120084 & 10.88692 \\
\hline$a_{2}$ & -0.008412 & -0.072549 & -0.053588 & -1.699325 \\
\hline$\omega$ & 1.059432 & 1.652918 & 0.045916 & 6.247615 \\
\hline$\beta$ & 0.127994 & 6.038508 & 0.127471 & 8.149657 \\
\hline$\gamma$ & 0.739826 & 11.78789 & 0.853192 & 55.08195 \\
\hline$\delta$ & 0.013068 & 0.85081 & 0.009906 & 5.726946 \\
\hline$\theta$ & -0.006997 & -2.478367 & -0.001099 & -7.288382 \\
\hline $\begin{array}{c}\text { LR(5) for } \\
H_{2}: a_{1}=\beta=\gamma=\delta=\theta=0\end{array}$ & \multicolumn{2}{|c|}{137.6379} & \multicolumn{2}{|c|}{8348.236} \\
\hline Log-likelihood & \multicolumn{2}{|c|}{-7661.213} & \multicolumn{2}{|c|}{-7204.954} \\
\hline \multirow[t]{3}{*}{ Number of obs. } & \multicolumn{2}{|c|}{3107} & \multicolumn{2}{|c|}{3107} \\
\hline & \multicolumn{2}{|c|}{ NNP } & \multicolumn{2}{|c|}{ BPM } \\
\hline & Coefficient & z-Statistic & Coefficient & $\mathrm{z}$-Statistic \\
\hline$a_{0}$ & -0.13845 & -0.912321 & -0.244826 & -1.580547 \\
\hline$a_{1}$ & 0.111597 & 9.477303 & 0.140348 & 8.979078 \\
\hline$a_{2}$ & -0.13845 & -0.912321 & -0.244826 & -1.580547 \\
\hline$\omega$ & 2.121423 & 1.668533 & 1.535185 & 1.707939 \\
\hline$\beta$ & 0.174468 & 6.44203 & 0.142946 & 6.009577 \\
\hline$\gamma$ & 0.586753 & 5.332544 & 0.656214 & 7.647856 \\
\hline$\delta$ & 0.007679 & 1.284744 & 0.025007 & 3.152169 \\
\hline$\theta$ & -0.001414 & -0.594126 & -0.005971 & -3.67016 \\
\hline $\begin{array}{c}\operatorname{LR}(5) \text { for } \\
H_{2}: a_{1}=\beta=\gamma=\delta=\theta=0\end{array}$ & \multicolumn{2}{|c|}{36.75007} & \multicolumn{2}{|c|}{283.0316} \\
\hline Log-likelihood & \multicolumn{2}{|c|}{-7752.475} & \multicolumn{2}{|c|}{-7639.46} \\
\hline Number of obs. & \multicolumn{2}{|c|}{3107} & \multicolumn{2}{|c|}{3107} \\
\hline
\end{tabular}

Panel B: Whole sample period (1993.07.15-2009.06.01): Firms with high price discount.

tical throughout the entire sample period. Thus, the empirical results indicate that the spillover effects for firms with a higher price discount were similar to those with a lower price discount for the entire sample period.

In this section, we find that price information spillover is very strong for both the high price disparity and low price disparity groups and we could not find any difference in the mean spillover between both groups (all four significant mean coefficients). In addition to this, we find that volatility spillover is smaller for both groups when the shock is coming from Hong Kong $\mathrm{H}$ shares to Chinese A shares (2 out of 4 significant volatility coefficients) than when the shock is coming from Chinese A shares to Hong Kong $\mathrm{H}$ shares (3 out of 4 significant volatility coefficients). However, we could not find a consistent pattern for the leverage spillover during this period.

\subsection{Analysis for the Pre-Liberalization Period}

The results of spillover effects in returns and volatilities from Chinese A shares to Hong Kong $\mathrm{H}$ shares for 
firms with low price discounts are presented in Table 6(a).

In Table 6(a), the coefficient of $a_{1}$ indicates that the spillover effect of price disparity for DME firms (the least price discount firm) was not significant, while for the other three high price disparities (TTB), the firms were significant. We also find that the estimated coefficient increases as we move from the least price discount firm to that of higher price discount firms within the low price disparity firm. This also confirms our hypothesis that a greater price disparity fosters a stronger transmission of pricing information.

The coefficients of $\delta$ indicating the spillover effect of volatility were significant for only 1 out of the 4 firms. This implies that there was very little volatility spillover within a low price discount group. The coefficients of $\theta$ that indicated the leverage effect were significant for 2 out of 4 firms.

Table 6(b) presents the results of the spillover effects in returns and volatilities from Chinese A shares to Hong Kong $\mathrm{H}$ shares for firms with a high price discount for the pre-liberalization period. In contrast to Table 6(a)

Table 6. (a) (b) Spillover effects in returns and volatilities from Chinese A shares to Hong Kong H shares during the pre-liberalization sub-sample period.

(a)

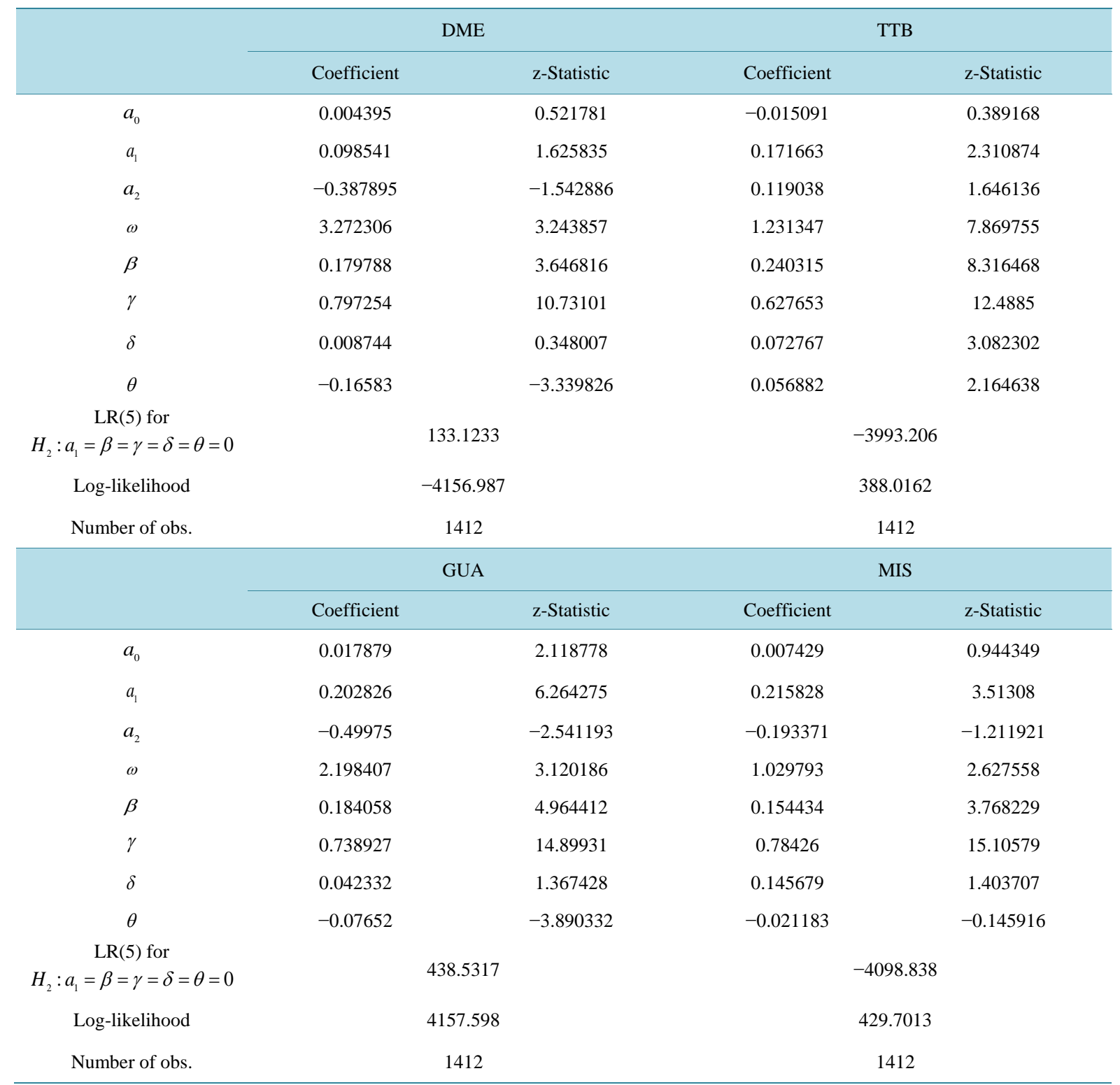

Panel A: Pre-liberalization sub-sample period (1993.07.15-2002.11.30): Firms with low price discount. 
(b)

\begin{tabular}{|c|c|c|c|c|}
\hline & \multicolumn{2}{|c|}{ LGC } & \multicolumn{2}{|c|}{ NET } \\
\hline & Coefficient & z-Statistic & Coefficient & z-Statistic \\
\hline$a_{0}$ & 0.00295 & 0.353275 & -0.001422 & -0.327558 \\
\hline$a_{1}$ & 0.185176 & 4.158664 & 0.244502 & 4.36713 \\
\hline$a_{2}$ & -0.1172 & -0.628034 & 0.000118 & 0.154247 \\
\hline$\omega$ & 1.778716 & 2.59762 & $6.25 \mathrm{E}-06$ & 2.371813 \\
\hline$\beta$ & 0.158441 & 3.763124 & 0.266078 & 14.05199 \\
\hline$\gamma$ & 0.765557 & 12.67373 & 0.693305 & 92.96825 \\
\hline$\delta$ & 0.003242 & 0.070626 & 0.584781 & 20.66442 \\
\hline$\theta$ & 0.109977 & 1.159964 & -0.000741 & -0.889181 \\
\hline $\begin{array}{l}\text { LR(5) for } \\
H_{2}: a_{1}=\beta=\gamma=\delta=\theta=0\end{array}$ & \multicolumn{2}{|c|}{139.7214} & \multicolumn{2}{|c|}{14004.31} \\
\hline Log-likelihood & \multicolumn{2}{|c|}{-4185.293} & \multicolumn{2}{|c|}{-3696.078} \\
\hline \multirow[t]{3}{*}{ Number of obs. } & \multicolumn{2}{|c|}{1412} & \multicolumn{2}{|c|}{1412} \\
\hline & \multicolumn{2}{|c|}{ NNP } & \multicolumn{2}{|c|}{ BPM } \\
\hline & Coefficient & z-Statistic & Coefficient & z-Statistic \\
\hline$a_{0}$ & 0.016676 & 1.643342 & 0.000916 & 0.067499 \\
\hline$a_{1}$ & 0.155484 & 2.415648 & 0.148966 & 3.222223 \\
\hline$a_{2}$ & -0.544726 & -1.812847 & -0.047924 & -0.223588 \\
\hline$\omega$ & 4.143507 & 3.031571 & 2.194708 & 2.524806 \\
\hline$\beta$ & 0.132243 & 3.680404 & 0.130111 & 3.099232 \\
\hline$\gamma$ & 0.696761 & 10.14292 & 0.716466 & 8.527691 \\
\hline$\delta$ & 0.224633 & 1.751331 & -0.013296 & -0.305587 \\
\hline$\theta$ & 0.021874 & 0.129622 & 0.200408 & 0.955503 \\
\hline $\begin{array}{l}\text { LR(5) for } \\
H_{2}: a_{1}=\beta=\gamma=\delta=\theta=0\end{array}$ & \multicolumn{2}{|c|}{139.7214} & \multicolumn{2}{|c|}{78.50075} \\
\hline Log-likelihood & \multicolumn{2}{|c|}{-4384.188} & \multicolumn{2}{|c|}{-3936.333} \\
\hline Number of obs. & \multicolumn{2}{|c|}{1412} & \multicolumn{2}{|c|}{1412} \\
\hline
\end{tabular}

Panel B: Pre-liberalization sub-sample period (1993.07.15-2002.11.30): Firms with high price discount.

, the coefficients of $a_{1}$ indicating the spillover effect of price disparity was all significant at the $1 \%$ level. These coefficients confirm that there was a strong transmission of pricing information for the high discount group, even in the pre-liberalization period. However, similar to Table 6(a), the coefficients of $\delta$ were significant for only 1 out of the 4 firms. This implies that there was very little volatility spillover. In general, the coefficients of $\theta$ indicating the leverage effect were not significant. These results suggest that no transmission of leverage information occurred.

The results of the spillover effects in returns and volatilities from Hong Kong $\mathrm{H}$ shares to Chinese A shares for firms with a low price discount are shown in Table 7(a) for the sub-period before December 2002. In the table, the coefficient of $a_{1}$ indicating the spillover effect of price disparity for DME firms was not significant, while that for the other three firms (TTB, GUA and MIS) were significant. However, the magnitudes of the coefficients were not strong. The coefficients of $\delta$ that indicated the spillover effect of volatility were significant 
for 2 out of the 4 firms. The coefficients of $\theta$ indicating the leverage effect were significant for only 1 out of the 4 firms.

Table 7(b) documents the results of the spillover effects in returns and volatilities from Hong Kong $\mathrm{H}$ shares to Chinese A shares for firms with high price discounts throughout the sub-period before December 2002. In contrast to Table 7(a), the coefficients of $a_{1}$ indicating the spillover effect of price disparity were all significant at the $1 \%$ level. However, the coefficients of $\delta$ were significant for 3 out of the 4 firms. Again, the coefficients of $\theta$ indicating the leverage effect were significant for only 1 out of the 4 companies, implying that there was very little leverage spillover.

The results from Table 6(a) to Table 7(b) showed that all the coefficients of $a_{1}, a_{2}, \beta, \gamma, \delta$, and $\theta$

Table 7. (a) (b) Spillover effects in returns and volatilities from Hong Kong H shares to Chinese A shares during the pre-liberalization sub-sample period.

(a)

\begin{tabular}{|c|c|c|c|c|}
\hline & \multicolumn{2}{|c|}{ DME } & \multicolumn{2}{|c|}{ ТTВ } \\
\hline & Coefficient & z-Statistic & Coefficient & z-Statistic \\
\hline$a_{0}$ & -0.059976 & -0.7946 & -0.008461 & -0.087012 \\
\hline$a_{1}$ & 0.006179 & 1.582683 & 0.042609 & 2.188269 \\
\hline$a_{2}$ & 0.042326 & 2.208636 & 0.00618 & 0.459168 \\
\hline$\omega$ & 0.142293 & 3.12616 & 0.502603 & 2.887021 \\
\hline$\beta$ & 0.112175 & 3.373827 & 0.159218 & 3.717644 \\
\hline$\gamma$ & 0.667473 & 23.96678 & 0.714276 & 12.8504 \\
\hline$\delta$ & -0.002259 & -2.531368 & 0.002802 & 0.425811 \\
\hline$\theta$ & -0.000562 & -0.685284 & 0.010285 & 0.720827 \\
\hline $\begin{array}{c}\mathrm{LR}(5) \text { for } \\
H_{2}: a_{1}=\beta=\gamma=\delta=\theta=0\end{array}$ & \multicolumn{2}{|c|}{2018.302} & \multicolumn{2}{|c|}{2211.4737} \\
\hline Log-likelihood & \multicolumn{2}{|c|}{-2359.185} & \multicolumn{2}{|c|}{-3231.549} \\
\hline \multirow[t]{3}{*}{ Number of obs. } & \multicolumn{2}{|c|}{1412} & \multicolumn{2}{|c|}{1412} \\
\hline & \multicolumn{2}{|c|}{ GUA } & \multicolumn{2}{|c|}{ MIS } \\
\hline & Coefficient & z-Statistic & Coefficient & z-Statistic \\
\hline$a_{0}$ & -0.026238 & -0.307127 & -0.074789 & -1.365561 \\
\hline$a_{1}$ & 0.055585 & 4.823341 & 0.035705 & 5.015528 \\
\hline$a_{2}$ & 0.002409 & 0.155469 & 0.002007 & 0.1495 \\
\hline$\omega$ & 1.027029 & 3.759111 & 0.526212 & 3.197192 \\
\hline$\beta$ & 0.29592 & 6.247337 & 0.307004 & 5.951404 \\
\hline$\gamma$ & 0.540119 & 9.967942 & 0.579105 & 9.234175 \\
\hline$\delta$ & 0.001452 & 0.520928 & 0.011047 & 2.601672 \\
\hline$\theta$ & 0.008547 & 0.953738 & -0.014052 & -2.930768 \\
\hline $\begin{array}{c}\mathrm{LR}(5) \text { for } \\
H_{2}: a_{1}=\beta=\gamma=\delta=\theta=0\end{array}$ & \multicolumn{2}{|c|}{83.19595} & \multicolumn{2}{|c|}{15978961} \\
\hline Log-likelihood & \multicolumn{2}{|c|}{-3175.335} & \multicolumn{2}{|c|}{-2935.758} \\
\hline Number of obs. & \multicolumn{2}{|c|}{1412} & \multicolumn{2}{|c|}{1412} \\
\hline
\end{tabular}

Panel A: Pre-liberalization sub-sample period (1993.07.15-2009.06.01): Firms with low price discount. 
(b)

\begin{tabular}{|c|c|c|c|c|}
\hline & \multicolumn{2}{|c|}{ LGC } & \multicolumn{2}{|c|}{ NET } \\
\hline & Coefficient & z-Statistic & Coefficient & z-Statistic \\
\hline$a_{0}$ & 0.02279 & 0.256946 & -0.000102 & -0.040165 \\
\hline$a_{1}$ & 0.053234 & 3.253329 & 0.070669 & 4.097602 \\
\hline$a_{2}$ & 0.02279 & 0.256946 & -0.000102 & -0.040165 \\
\hline$\omega$ & 0.931817 & 3.912567 & 0.000203 & 0.980761 \\
\hline$\beta$ & 0.271105 & 6.744099 & 0.470063 & 2.181183 \\
\hline$\gamma$ & 0.522207 & 6.552234 & 0.536494 & 9.060153 \\
\hline$\delta$ & 0.027138 & 2.307403 & 0.055595 & 2.565888 \\
\hline$\theta$ & 0.061446 & 1.438693 & 0.02507 & 1.359663 \\
\hline $\begin{array}{c}\text { LR(5) for } \\
H_{2}: a_{1}=\beta=\gamma=\delta=\theta=0\end{array}$ & \multicolumn{2}{|c|}{109.2334} & \multicolumn{2}{|c|}{238.8068} \\
\hline Log-likelihood & \multicolumn{2}{|c|}{-3350.824} & \multicolumn{2}{|c|}{-2915.807} \\
\hline \multirow[t]{3}{*}{ Number of obs. } & \multicolumn{2}{|c|}{1412} & \multicolumn{2}{|c|}{1412} \\
\hline & \multicolumn{2}{|c|}{ NNP } & \multicolumn{2}{|c|}{ ВРM } \\
\hline & Coefficient & z-Statistic & Coefficient & z-Statistic \\
\hline$a_{0}$ & -0.106117 & -1.08439 & 0.013708 & 0.122391 \\
\hline$a_{1}$ & 0.040314 & 3.261268 & 0.055045 & 2.950001 \\
\hline$a_{2}$ & -0.106117 & -1.08439 & 0.013708 & 0.122391 \\
\hline$\omega$ & 0.703685 & 3.783244 & 0.899935 & 3.583087 \\
\hline$\beta$ & 0.22179 & 6.117583 & 0.195002 & 5.587331 \\
\hline$\gamma$ & 0.628204 & 11.63604 & 0.644826 & 10.99474 \\
\hline$\delta$ & 0.008604 & 2.192822 & 0.023938 & 3.271034 \\
\hline$\theta$ & 0.004713 & 1.225577 & -0.0046 & -9.274368 \\
\hline $\begin{array}{c}\text { LR(5) for } \\
H_{2}: a_{1}=\beta=\gamma=\delta=\theta=0\end{array}$ & \multicolumn{2}{|c|}{$163.761^{* *}$} & \multicolumn{2}{|c|}{187.0681} \\
\hline Log-likelihood & \multicolumn{2}{|c|}{-3214.728} & \multicolumn{2}{|c|}{3284.062} \\
\hline Number of obs. & \multicolumn{2}{|c|}{1412} & \multicolumn{2}{|c|}{1412} \\
\hline
\end{tabular}

Panel B: Pre-liberalization sub-sample period (1993.07.15-2009.06.01): Firms with high price discount.

were not zero. The log-likelihood statistics was not accepted at the $1 \%$ significance level, showing that the model appeared to be adequate.

In this section, we find significant differences in estimates of the mean spillover coefficients in the low price discount group and high price discount group during the pre-liberalization period. The empirical results show that a mean spillover effect for the higher price discount group is greater than those for the lower price discount group for shocks coming from either direction. However, the volatility spillover effect is stronger when the shock comes from Hong Kong for both groups.

\subsection{Analysis of Post-Liberalization Period}

The results of the spillover effects in returns and volatilities from Chinese A shares to Hong Kong $\mathrm{H}$ shares for the firms with a low price discount are presented in Table 8(a) for the sub-period after December 2002. In the 
table, the coefficients of $a_{1}$ that indicated the spillover effect of price disparity were all significant at the $1 \%$ level. The coefficients of $\delta$ indicating the spillover effect of volatility were significant for 2 out of the 4 firms. The coefficients of $\theta$ indicating a leverage effect were not significant at all.

Table 8(b) presents the results of the spillover effects in returns and volatilities from Chinese A shares to Hong Kong $\mathrm{H}$ shares for firms with high price discounts for the sub-period after December 2002. Similar to Table 8(a), the coefficients of $a_{1}$ that indicated the spillover effect of price disparity were all significant at the $1 \%$ level. Likewise, the coefficients of $\delta$ were significant for 2 out of 4 firms. However, the coefficients of $\theta$ indicating a leverage effect were significant for 2 out of 4 firms. This tells us that the leverage spillover is greater for the high price discount firms.

Table 8. (a) (b) Spillover effects in returns and volatilities from Chinese A shares to Hong Kong H shares during the postliberalization sub-sample period.

(a)

\begin{tabular}{|c|c|c|c|c|c|}
\hline & \multicolumn{2}{|c|}{ DME } & \multicolumn{3}{|c|}{ ТTВ } \\
\hline & Coefficient & z-Statistic & Coefficient & & z-Statistic \\
\hline$a_{0}$ & -0.024376 & -1.543743 & -0.013091 & & -0.679491 \\
\hline$a_{1}$ & 0.202217 & 5.127257 & 0.267663 & & 8.912774 \\
\hline$a_{2}$ & 0.568915 & 2.700352 & 0.195038 & & 1.50615 \\
\hline$\omega$ & 4.454202 & 3.105312 & 1.131348 & & 3.439441 \\
\hline$\beta$ & 0.125682 & 1.310968 & 0.140315 & & 3.550792 \\
\hline$\gamma$ & 0.40645 & 2.129709 & 0.627653 & & 9.653939 \\
\hline$\delta$ & 0.172011 & 1.981288 & 0.072767 & & 2.364137 \\
\hline$\theta$ & 0.010221 & 0.270755 & 0.056882 & & 1.301653 \\
\hline $\begin{array}{c}\operatorname{LR}(5) \text { for } \\
H_{2}: a_{1}=\beta=\gamma=\delta=\theta=0\end{array}$ & \multicolumn{2}{|c|}{23.10198} & \multicolumn{3}{|c|}{79.59721} \\
\hline Log-likelihood & \multicolumn{2}{|c|}{-4541.28} & \multicolumn{3}{|c|}{-3993.206} \\
\hline \multirow[t]{3}{*}{ Number of obs. } & \multicolumn{2}{|c|}{1695} & \multicolumn{3}{|c|}{1695} \\
\hline & \multicolumn{2}{|c|}{ GUA } & \multicolumn{3}{|c|}{ MIS } \\
\hline & Coefficient & z-Statistic & Coefficient & & z-Statistic \\
\hline$a_{0}$ & 0.029067 & 2.652249 & 0.013725 & & 1.284577 \\
\hline$a_{1}$ & 0.318125 & 12.0381 & 0.324016 & & 13.87482 \\
\hline$a_{2}$ & -0.209995 & -1.467092 & 0.010016 & & 0.119738 \\
\hline$\omega$ & 1.374476 & 3.384799 & 0.023505 & & 1.779874 \\
\hline$\beta$ & 0.193195 & 4.204529 & 0.051174 & & 7.932584 \\
\hline$\gamma$ & 0.67495 & 10.80461 & 0.932029 & & 126.1518 \\
\hline$\delta$ & 0.071739 & 2.571486 & 0.018767 & & 6.483785 \\
\hline$\theta$ & -0.028617 & -1.204233 & -0.002269 & & -22.4568 \\
\hline $\begin{array}{c}\operatorname{LR}(5) \text { for } \\
H_{2}: a_{1}=\beta=\gamma=\delta=\theta=0\end{array}$ & \multicolumn{2}{|c|}{205.4001} & & & \\
\hline Log-likelihood & \multicolumn{2}{|c|}{-4533.023} & \multicolumn{3}{|c|}{-4215.634} \\
\hline Number of obs. & \multicolumn{2}{|c|}{1695} & \multicolumn{3}{|c|}{1695} \\
\hline
\end{tabular}

Panel A: Post -liberalization sub-sample period (2002.12.01-2009.06.01): Firms with low price discount. 
(b)

\begin{tabular}{|c|c|c|c|c|}
\hline & \multicolumn{2}{|c|}{ LGC } & \multicolumn{2}{|c|}{ NET } \\
\hline & Coefficient & z-Statistic & Coefficient & z-Statistic \\
\hline$a_{0}$ & -0.010748 & -0.800218 & -0.000266 & -0.039049 \\
\hline$a_{1}$ & 0.147019 & 5.529475 & 0.046439 & 2.787075 \\
\hline$a_{2}$ & 0.333992 & 3.50824 & -0.041457 & -0.314259 \\
\hline$\omega$ & 0.605237 & 4.971441 & 5.807653 & 3.823921 \\
\hline$\beta$ & 0.145801 & 4.967656 & 0.254013 & 3.212124 \\
\hline$\gamma$ & 0.430746 & 15.43345 & 0.180134 & 1.560194 \\
\hline$\delta$ & 0.000818 & 0.179694 & 0.91789 & 2.032888 \\
\hline$\theta$ & -0.013253 & -7.263017 & 0.038089 & 0.349076 \\
\hline $\begin{array}{l}\text { LR(5) for } \\
H_{2}: a_{1}=\beta=\gamma=\delta=\theta=0\end{array}$ & \multicolumn{2}{|c|}{3275.679} & \multicolumn{2}{|c|}{120.5251} \\
\hline Log-likelihood & \multicolumn{2}{|c|}{-3676.269} & \multicolumn{2}{|c|}{-4803.723} \\
\hline \multirow[t]{3}{*}{ Number of obs. } & \multicolumn{2}{|c|}{1695} & \multicolumn{2}{|c|}{1695} \\
\hline & \multicolumn{2}{|c|}{ NNP } & \multicolumn{2}{|c|}{ BPM } \\
\hline & Coefficient & z-Statistic & Coefficient & z-Statistic \\
\hline$a_{0}$ & 0.013873 & 0.882743 & 0.010335 & 1.050928 \\
\hline$a_{1}$ & 0.321808 & 11.44445 & 0.232892 & 7.921508 \\
\hline$a_{2}$ & -0.157709 & -0.754295 & -0.079665 & -0.888539 \\
\hline$\omega$ & 4.380666 & 2.716264 & 1.521202 & 4.532172 \\
\hline$\beta$ & 0.153753 & 2.890563 & 0.306757 & 5.878637 \\
\hline$\gamma$ & 0.36902 & 3.713293 & 0.432921 & 7.024026 \\
\hline$\delta$ & 0.060351 & 1.615065 & 0.174588 & 3.642029 \\
\hline$\theta$ & 0.188021 & 1.568797 & -0.002126 & -3.301077 \\
\hline $\begin{array}{l}\text { LR(5) for } \\
H_{2}: a_{1}=\beta=\gamma=\delta=\theta=0\end{array}$ & \multicolumn{2}{|c|}{32.16127} & \multicolumn{2}{|c|}{104.9082} \\
\hline Log-likelihood & \multicolumn{2}{|c|}{-4489.871} & \multicolumn{2}{|c|}{-4237.116} \\
\hline Number of obs. & \multicolumn{2}{|c|}{1695} & \multicolumn{2}{|c|}{1695} \\
\hline
\end{tabular}

Panel B: Post -liberalization sub-sample period (2002.12.01-2009.06.01): Firms with high price discount.

The results of the spillover effects from Hong Kong $\mathrm{H}$ shares to Chinese A shares for firms with low price discounts are reported in Table 9(a) for the sub-period after December 2002. In the table, the coefficients of $a_{1}$ that indicated the spillover effect of price disparity were all significant. The coefficients of $\delta$ indicating the spillover effect of volatility were significant for 2 out of 4 firms. The coefficients of $\theta$ indicating a leverage effect were not significant at all.

Table 9(b) documents the results of spillover effects in returns and volatilities from Hong Kong $\mathrm{H}$ shares to Chinese A shares for firms with high price discounts for the sub-period after December 2002.

Similarly to Table 9(a), the coefficients of $a_{1}$ that indicated the spillover effect of price disparity were all significant. The coefficients of $\delta$ were significant for 2 out of the 4 firms. The coefficients of $\theta$ indicating a leverage effect were not significant at all.

The results from Table 8(a) to Table 9(b) showed that all the coefficients of $a_{1}, a_{2}, \beta, \gamma, \delta$, and $\theta$ were not 
zero. The log-likelihood statistics was rejected at the $1 \%$ significant level, indicating that the model appeared to be adequate. Overall, the results of panel A and panel B were not different throughout the post-liberalization period.

In this section, we find that mean spillover effect is very strong for both groups of firms during the post-liberalization period. There is also a stronger mean spillover effect for the high price disparity group compared to the low price disparity group in the pre-liberalization period, which disappears in the post-liberalization period. When we focus on volatility spillover, we find that the volatility spillover from the Chinese A market to the Hong Kong $\mathrm{H}$ market increased during the post-liberalization period than the pre-liberalization period while the volatility spillover from the Hong Kong $\mathrm{H}$ market to the Chinese A market decreased during the post-liberalization period for the high price disparity group.

Table 9. (a) (b) Spillover effects in returns and volatilities from Hong Kong $\mathrm{H}$ shares to Chinese A shares during the postliberalization sub-sample period.

(a)

\begin{tabular}{|c|c|c|c|c|}
\hline & \multicolumn{2}{|c|}{ DME } & \multicolumn{2}{|c|}{ ТTВ } \\
\hline & Coefficient & z-Statistic & Coefficient & z-Statistic \\
\hline$a_{0}$ & 0.003825 & 0.376429 & 0.004831 & 0.518198 \\
\hline$a_{1}$ & 0.09285 & 5.009414 & 0.186405 & 8.122985 \\
\hline$a_{2}$ & -0.103467 & -1.077042 & 0.032563 & 2.114176 \\
\hline$\omega$ & 0.1451 & 1.83938 & -0.0399 & -3.234599 \\
\hline$\beta$ & 0.081207 & 4.821946 & 0.089282 & 4.614644 \\
\hline$\gamma$ & 0.910375 & 50.53407 & 0.894026 & 41.3173 \\
\hline$\delta$ & -0.007008 & -1.44758 & 0.026768 & 1.983675 \\
\hline$\theta$ & 0.011818 & 1.667389 & -0.004157 & -0.306952 \\
\hline $\begin{array}{c}\mathrm{LR}(5) \text { for } \\
H_{2}: a_{1}=\beta=\gamma=\delta=\theta=0\end{array}$ & \multicolumn{2}{|c|}{4366.064} & \multicolumn{2}{|c|}{8864.138} \\
\hline Log-likelihood & \multicolumn{2}{|c|}{-4243.723} & \multicolumn{2}{|c|}{-3636.72} \\
\hline Number of obs. & \multicolumn{2}{|c|}{1695} & \multicolumn{2}{|c|}{1695} \\
\hline & \multicolumn{2}{|c|}{ GUA } & \multicolumn{2}{|c|}{ MIS } \\
\hline & Coefficient & z-Statistic & Coefficient & z-Statistic \\
\hline$a_{0}$ & 0.001459 & 0.115389 & 0.000389 & 0.002439 \\
\hline$a_{1}$ & 0.275278 & 12.38782 & 0.312477 & 10.56814 \\
\hline$a_{2}$ & 0.016852 & 0.133755 & -0.084497 & -0.038726 \\
\hline$\omega$ & 0.537283 & 2.750701 & 24.34675 & 8.054336 \\
\hline$\beta$ & 0.118358 & 5.890429 & -0.006476 & -1.690886 \\
\hline$\gamma$ & 0.780881 & 20.97566 & -0.752332 & -3.80325 \\
\hline$\delta$ & 0.030422 & 3.265706 & -0.005519 & -0.60076 \\
\hline$\theta$ & 0.019595 & 0.99159 & -0.049423 & -1.2915 \\
\hline $\begin{array}{c}\mathrm{LR}(5) \text { for } \\
H_{2}: a_{1}=\beta=\gamma=\delta=\theta=0\end{array}$ & \multicolumn{2}{|c|}{535.7075} & \multicolumn{2}{|c|}{52.11751} \\
\hline Log-likelihood & \multicolumn{2}{|c|}{-4330.943} & \multicolumn{2}{|c|}{-4274.885} \\
\hline Number of obs. & \multicolumn{2}{|c|}{1695} & \multicolumn{2}{|c|}{1695} \\
\hline
\end{tabular}

Panel A: Post -liberalization sub-sample period (2002.12.01-2009.06.01): Firms with low price discount 
(b)

\begin{tabular}{|c|c|c|c|c|}
\hline & \multicolumn{2}{|c|}{ LGC } & \multicolumn{2}{|c|}{ NET } \\
\hline & Coefficient & z-Statistic & Coefficient & z-Statistic \\
\hline$a_{0}$ & 0.009128 & 0.385997 & 0.001624 & 0.195741 \\
\hline$a_{1}$ & 0.224331 & 7.304003 & 0.08102 & 2.726121 \\
\hline$a_{2}$ & -0.109979 & -0.499193 & 0.018698 & 0.937503 \\
\hline$\omega$ & 0.656726 & 0.927399 & 0.017411 & 3.068831 \\
\hline$\beta$ & 0.062535 & 3.042737 & 0.147246 & 6.676775 \\
\hline$\gamma$ & 0.873757 & 14.45563 & 0.876625 & 52.17022 \\
\hline$\delta$ & -0.005517 & -0.258278 & -0.000252 & -1.247699 \\
\hline$\theta$ & -0.007314 & -0.350348 & -0.000103 & -0.646913 \\
\hline $\begin{array}{c}\operatorname{LR}(5) \text { for } \\
H_{2}: a_{1}=\beta=\gamma=\delta=\theta=0\end{array}$ & \multicolumn{2}{|c|}{344.9123} & \multicolumn{2}{|c|}{6351.403} \\
\hline Log-likelihood & \multicolumn{2}{|c|}{-4253.249} & \multicolumn{2}{|c|}{-3727.25} \\
\hline \multirow[t]{3}{*}{ Number of obs. } & \multicolumn{2}{|c|}{1695} & \multicolumn{2}{|c|}{1695} \\
\hline & \multicolumn{2}{|c|}{ NNP } & \multicolumn{2}{|c|}{ BPM } \\
\hline & Coefficient & z-Statistic & Coefficient & z-Statistic \\
\hline$a_{0}$ & -0.000735 & -0.03348 & 0.028445 & 1.190163 \\
\hline$a_{1}$ & 0.313946 & 12.79442 & 0.262032 & 10.44527 \\
\hline$a_{2}$ & 0.018635 & 0.078738 & -0.289469 & -1.171585 \\
\hline$\omega$ & 5.178421 & 1.916575 & 1.662098 & 1.126683 \\
\hline$\beta$ & 0.135276 & 2.998484 & 0.123745 & 3.758302 \\
\hline$\gamma$ & 0.332547 & 1.683367 & 0.654014 & 5.476848 \\
\hline$\delta$ & 0.055662 & 3.358497 & 0.037613 & 2.784344 \\
\hline$\theta$ & -0.002916 & -0.990508 & 0.036016 & 1.291587 \\
\hline $\begin{array}{c}\operatorname{LR}(5) \text { for } \\
H_{2}: a_{1}=\beta=\gamma=\delta=\theta=0\end{array}$ & \multicolumn{2}{|c|}{39.24289} & \multicolumn{2}{|c|}{27.46854} \\
\hline Log-likelihood & \multicolumn{2}{|c|}{-4404.51} & \multicolumn{2}{|c|}{-4297.874} \\
\hline Number of obs. & \multicolumn{2}{|c|}{1695} & \multicolumn{2}{|c|}{1695} \\
\hline
\end{tabular}

Panel B: Post-liberalization sub-sample period. (2002.12.01-2009.06.01): Firms with high price discount.

\section{Summary and Conclusion}

Following the opening of the securities markets in the early 1990s, the stock markets in China have been growing rapidly. China established separate classes of shares for Chinese citizens and for foreigners. Domestic-only, or A shares, are listed in either the Shanghai Stock Exchange (SHSE) or the Shenzhen Stock Exchange (SZSE), while the foreigner-only stocks are listed in Shanghai or Shenzhen (B shares) or in Hong Kong (H shares). The A shares, $\mathrm{B}$ shares, and $\mathrm{H}$ shares are legally identical and provide the same voting rights and cash flow. However, they differ only in who can own them. In contrast to many other countries, China's stock market has substantial and persistent price discounts on foreign-only B shares relative to the domestic-only A shares. This is known 
as the "Chinese Stock Market Puzzle”. Similarly, the H shares available in the Hong Kong market also show price discounts relative to the A shares. However, in February 2001, China allowed domestic investors to trade in B share stocks and Qualified Foreign Institutional Investors (QFII) had also been allowed to trade in A share stocks in December 2002. This deregulation should have an impact on the price disparity and transmission of information between Hong Kong and Chinese markets. This study investigated the spillover of pricing and volatility information with respect to stocks dual-listed on both the Chinese and Hong Kong markets. The spillover effect should be more clearly detectable when the trading hours of both markets are somewhat concurrent, as is the case between the Hong Kong and Chinese market.

In comparison to previous studies, we analyzed the spillover effect at a firm-specific level. We believed that if the price discount or price disparity for the dual-listed stocks was large, the effect of price disparity on the transmission of information between the two shares would be strong because of an increasing price arbitrage. This paper made the following contributions. First, it was the first study to investigate the spillover effect by directly comparing companies with a low price discount to those with a high price discount. Second, the transmission of information was examined, not only for the entire sample period, but also for the sub-sample periods, including pre- and post-liberalization. Third, the current study applied the GJR-GARCH model to analyze the spillover effect. It is widely agreed that the GJR-GARCH model is appropriate to capture the symmetric spillover effect, as well as the asymmetric spillover effect.

From this analysis, we find significant differences in estimates of mean spillover coefficients between a low price discount group and a high price discount group during the pre-liberalization period. The empirical results show that a mean spillover effect for the higher price discount group is stronger than that for the lower price discount group for shocks coming from either direction. However, the volatility spillover effect is stronger when the shock is coming from Hong Kong for both groups of firms.

We also find that the mean spillover effect is very strong for both groups of firms during the post-liberalization period and there is a stronger mean spillover effect for the high price disparity group compared to the low price disparity group in pre-liberalization, which disappeared in the post-liberalization period. When we focused on volatility spillover, we found that the volatility spillover from the Chinese A market to the Hong Kong $\mathrm{H}$ market increased during the post-liberalization period than the pre-liberalization period while the volatility spillover from the Hong Kong H market to Chinese A market decreased during the post-liberalization period for the high price disparity group. However, we could not find consistent patterns for leverage spillovers.

Overall, the empirical results showed the transmission of pricing information was much stronger (i) during the post-liberalization period than the pre-liberalization period and for (ii) the high price disparity group than the low price disparity group. While this study used the daily return data, we found that using intraday return data would provide much more valuable insight about the mean and volatility spillover between both markets.

\section{References}

Bailey, W. (1994). Risk and Return on China’s New Stock Markets: Some Preliminary Evidence. Pacific-Basin Finance Journal, 2, 243-260. http://dx.doi.org/10.1016/0927-538X(94)90019-1

Bollerslev, T. (1986). Generalized Autoregressive Conditional Heteroskedasticity. Journal of Econometrics, 31, $307-327$. http://dx.doi.org/10.1016/0304-4076(86)90063-1

Cai, C., McGuinness, P., \& Zhang, Q. (2012). The Pricing Dynamics of Cross-Listed Securities: The Case of Chinese A- and H-Shares. Journal of Banking \& Finance, 35, 2123-2136. http://dx.doi.org/10.1016/j.jbankfin.2011.01.010

Chakravarty, S., Sarkar, A., \& Wu, L. (1998). Information Asymmetry, Market Segmentation and Pricing of Cross-Listed Shares: Theory and Evidence from Chinese A and B Shares. Journal of International Financial Markets, Institutions and Money, 8, 325-356. http://dx.doi.org/10.1016/S1042-4431(98)00041-9

Chen, G., Lee, B., \& Rui, O. (2001). Foreign Ownership Restriction and Market Segmentation in China’s Stock Markets. Journal of Financial Research, 24, 133-155. http://dx.doi.org/10.1111/j.1475-6803.2001.tb00822.x

Chong, T., \& Su, Q. (2006). On the Comovement of A and H Shares. Chinese Economy, 39, 68-86. http://dx.doi.org/10.2753/CES1097-1475390504

Engle, R. (1982). Autoregressive Conditional Heteroscedasticity with Estimates of the Variance of United Kingdom Inflation. Econometrica, 50, 525-542. http://dx.doi.org/10.2307/1912773

Glosten, L., Jagannathan, R., \& Runkle, D. (1993). On the Relation between the Expected Value and the Volatility of the Nominal Excess Return on Stocks. Journal of Finance, 48, 1779-1801. 
http://dx.doi.org/10.1111/j.1540-6261.1993.tb05128.x

Kim, K. (2011). An Analysis of the Transmission of Pricing Information of Stock Market Indices between Chinese and Hong Kong Stock Markets. Korean Journal of International Business Studies, 22, 1-27.

Kim, K., \& Choi, J. (2009). A Study on Price Discounts of H Shares Relative to A Shares in the Chinese Stock Market. Korean Journal of Financial Studies, 38, 231-255.

Kutan, A., \& Zhou, H. (2006). Determinants of Returns and Volatility of Chinese ADRs at NYSE. Journal of Multinational Financial Management, 16, 1-15. http://dx.doi.org/10.1016/j.mulfin.2005.02.003

Lee, B., Rui, O., \& Wu, W. (2008). Market Segmentation and Stock Prices Discount in the Chinese Stock Market: Revisiting B-Share Discounts in the Chinese Stock Market. Asia-Pacific Journal of Financial Studies, 37, 1-40.

Li, B. J., Yi, R. H., \& Su, R. (2011). Spillover Effect of Chinese Cross-Listed Companies across Shanghai, Hong Kong and US Markets. International Journal of Economics and Finance, 3, 135-140. http://dx.doi.org/10.5539/ijef.v3n6p135

Ma, X. (1996). Capital Controls, Market Segmentation and Stock Prices: Evidence from the Chinese Stock Market. PacificBasin Finance Journal, 4, 219-239. http://dx.doi.org/10.1016/0927-538X(96)00012-1

Peng, W., Miao, H., \& Chow, N. (2007). Price Convergence between Dual-Listed A and H Shares. Chinese Economic Issues, Number 6/07, 1-14.

Wang, Y., \& Iorio, A. (2007). Are the China-Related Stock Markets Segmented with Both World and Regional Stock Markets? Journal of International Financial Markets, Institutions and Money, 17, 277-290. http://dx.doi.org/10.1016/j.intfin.2005.12.001

Wei, P., \& Zeng, B. (2011). The Role of Liquidity in International Cross-Listing Effects: The Case of Chinese H and N Shares. Journal of Accounting and Finance, 11, 65-74.

Xu, E., \& Fung, H. (2002). Information Flows across Markets: Evidence from China-Backed Stocks Dual-Listed in Hong Kong and New York. Financial Review, 37, 563-588. http://dx.doi.org/10.1111/1540-6288.00029

Zhang, Y., \& Zhao, R. (2003). Risk under "One Country and Two Systems”: Evidence from Class A, B and H Shares of Chinese Listed Companies. Review of Pacific Basin Financial Markets and Policies, 6, 179-197. http://dx.doi.org/10.1142/S0219091503001067 